Türkiye Tarımsal Araştırmalar Dergisi
http://dergi.sirt.edu.tr $\begin{aligned} & \text { Turk J Agric Res } \\ & \text { (2015) 2: 108-113 } \\ & \text { TÜTAD } \\ & \text { ISSN: 2148-2306 }\end{aligned}$

\title{
Bingöı İli Merkez İlçesi Tarım Topraklarının Bazı Özellikleri ve Verimlilik Düzeyleri
}

\author{
Kadriye ATEŞ ${ }^{*}$, Veysel TURAN ${ }^{2}$

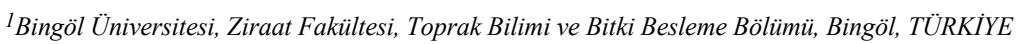 \\ ${ }^{2}$ Bingöl Üniversitesi, Ziraat Fakültesi, Biyosistem Mühendisliği Bölümü, Bingöl, TÜRKIYYE
}

\begin{abstract}
Geliș Tarihi/Received: 18.06 .2015
Kabul Tarihi/Accepted: 18.09 .2015

"Sorumlu Yazar/Correspondence: kates@bingol.edu.tr

Özet: Bu çalışma, 2014 yılında Bingöl ili Merkez ilçesindeki tarım topraklarının bazı toprak özellikleri ve verimlilik düzeylerini belirlemek amacıyla yapılmıştır. Topraklar; gayeli örnekleme metoduna göre $0-20 \mathrm{~cm}$ toprak derinliğinden, yer koordinatları belirlenerek, toplam 29 noktadan alınmıștır. Toprak örnekleri alınırken, arazi büyüklüğü, topoğrafik yapı gibi faktörler göz önünde bulundurulmuştur. Alınan örneklerde; suyla doygunluk (\%), $\mathrm{pH}$, toplam tuz (\%), kireç (\%), organik madde (\%), alınabilir fosfor $\left(\mathrm{kg} \mathrm{P}_{2} \mathrm{O}_{5} \mathrm{da}^{-1}\right)$ ve alınabilir potasyum $\left(\mathrm{kg} \mathrm{K}_{2} \mathrm{O} \mathrm{da}{ }^{-1}\right)$ analizleri yapılmıștır. Araştırma sonucuna göre, Bingöl ili Merkez ilçesi tarım topraklarının; genel olarak killi-tın bünyeli ve nötr veya nötre yakın reaksiyonlu olduğu, tuzluluk problemi bulunmayan toprakların kireç içeriğinin az kireçli ile orta kireçli arasında değiştiği, organik madde miktarının ise düşük düzeyde olduğu belirlenmiştir. İncelenen toprakların büyük çoğunluğu; alınabilir fosfor bakımından yetersiz, alınabilir potasyum bakımından ise yeterli bulunmuştur.
\end{abstract}

Anahtar Kelimeler: Bingöl, bitki besin maddesi, toprak verimliliği

\section{Some Soil Characteristics and the Fertility Status of Agricultural Soils in Bingöl Central District}

\begin{abstract}
This study was conducted in 2014 of agricultural land in the central district of Bingöl province in order to determine the levels of some soil properties and productivity levels. Soils were taken from $0-20 \mathrm{~cm}$ depth by purpose full sampling method and location coordinates were taken from a total of 29 points set with Global Positioning System. While getting soil samples, the size of the land is taken into account factor such as topography. This soil samples; lime (\%), $\mathrm{pH}$, salt (\%), water saturation (\%), organic matter (\%), available phosphorus $\left(\mathrm{P}_{2} \mathrm{O}_{5} \mathrm{~kg} \mathrm{da}^{-1}\right)$, available potassium $\left(\mathrm{K}_{2} \mathrm{O}\left(\mathrm{kg} \mathrm{da}^{-1}\right)\right.$ analyses were made. In general, the experimental soils have clay-loam texture, neutral or near neutral in reaction $(\mathrm{pH})$, without salt, low and moderate level calcareous, low organic matter. The majority of analyzed soils were found to be deficient in terms of phosphorus and sufficient in terms of potassium.
\end{abstract}

Keywords: Bingöl, plant nutrient, soil fertility

\section{Giriş}

İnsanoğlunun varoluşundan günümüze kadar en önemli ihtiyacı beslenmedir. Diğer ülkelerde olduğu gibi, ülkemizde de, sınırlı doğal kaynaklardan yararlanarak hızla artan nüfusu; yeterli, dengeli ve sağlıklı besleyebilmek için yeterince önlemlerin alınması gerekmektedir.
Tarımsal üretimde verim üzerine etkili olan en önemli faktörlerden birisi toprak verimliliğidir. Toprağın birim alanından alınacak ürün miktarının arttırılması iyi bir toprak yönetimine bağlıdır.

Aşırı ve bilinçsiz gübre uygulamaları toprak kirliliğine, yerüstü ve yeraltı sularının kirlenmesine neden olmakta (Parlak ve ark., 2008) 
ve bunun sonucu olarak bitkisel üretimde verim ve kalite düşüklüğü ortaya çıkmaktadır. Bu nedenle uygun ve dengeli gübre kullanımı, toprak sağlığ1 ve verimliliği açısından büyük önem taşımaktadır. Öte yandan, sanayileşme ve çarpık kentleşme sonucu kullanılan alanları gittikçe daralan ve hızla kirlenen tarım topraklarımızın sürdürülebilirliği için, toprakların fiziksel ve kimyasal özelliklerinin iyi bir şekilde bilinmesi ve bu özelliklere göre gerekli tedbirlerin alınması bir zorunluluk haline gelmiştir (Taban ve ark., 2004). Bu nedenle toprak analizlerine gereken önem verilmeli ve tarım yapılan toprakların verimlilik durumları belirlenerek, bitki cins ve türüne göre verilecek gübre çeşit ve miktarları saptanmalıdır.

Bursa ilinin değişik yörelerinden alınan toplam 1018 adet toprak örneğinde yapılan analizler sonucunda (Başar, 2001); incelenen toprakların, genellikle orta bünyeli, tuzluluk sorunu olmayan, hafif ve kuvvetli alkalin reaksiyonda ve değişik miktarlarda kireç içerdikleri; toprakların $\%$ 56.49'unun organik madde, \% 21.81'inin alınabilir fosfor (P) ve \% 21.82'sinin ise alınabilir potasyum $(\mathrm{K})$ içeriklerinin düşük ve çok düşük düzeylerde olduğu belirlenmiştir. Konya'nın Beyşehir ilçesinde 48 adet toprak örneği alınarak yürütülen bir çalışmada (Zengin ve ark., 2003); incelenen toprakların genellikle tın bünyeli, hafif alkalin pH'da, tuzsuz, orta kireçli ve düşük organik maddeli olduğu; toprakların azot $(\mathrm{N}), \mathrm{P}, \mathrm{K}$, demir $(\mathrm{Fe})$, bakır $(\mathrm{Cu})$, mangan $(\mathrm{Mn})$ ve çinko $(\mathrm{Zn})$ ortalamalarının sirasiyla $104.73,24.48,502.59$, $15.62, \quad 5.84, \quad 2.74$ ve $2.62 \mathrm{ppm}$ olduğu bildirilmektedir.

Çanakkale ili Lapseki ilçesi tarım topraklarında yürütülen bir çalışmada; bölge topraklarının yüksek miktarda kireç içerdiği; alkalin reaksiyonlu olan toprakların, organik madde ve alınabilir $\mathrm{P}$ içeriklerinin az, potasyumca zengin düzeyde olduğu; incelenen toprak örneklerinin \% 70'inde alınabilir $\mathrm{Zn}$ ve Fe içeriklerinin, \% 55'inde ise $\mathrm{Mn}$ içeriğinin az, \% 95'inde de alınabilir $\mathrm{Cu}$ miktarının yeterli seviyede olduğu tespit edilmiştir (Demirer ve ark., 2003). Çanakkale'de yürütülen bir başka çalışmada (Parlak ve ark., 2008) da benzer sonuçlar elde edilmiştir.

Van ili ve çevresinde buğday tarımı yapılan toprakları temsil edecek şekilde toplam 52 toprak örneği alınarak yürütülen araştırma sonucuna göre; toprakların \% 11.5'inin azotça fakir, \% 36.5'inin orta, \% 46'sının iyi ve \% 6'sının ise azot bakımından zengin durumda olduğu belirlenmiştir. Aynı toprakların alınabilir $\mathrm{P}$ yönünden; $\% 30.8$ 'inin çok az, \% 50'sinin az, \% 19'unun ise orta düzeyde olduğu; Heybeli köyü toprak örnekleri hariç tüm toprak örneklerinin değişebilir
$\mathrm{K}$ içerikleri bakımından yeter ve çok yüksek düzeyde oldukları saptanmıştır (Çimrin ve Boysan, 2006).

Ülkemiz genelinde yapılan diğer birçok çalışmalarla (Sungur ve Özuygur, 1986; Eyüpoğlu ve ark., 1996; Tarakçığlu ve ark., 2003; Adiloğlu ve Adiloğlu, 2004; Tümsavaş ve Aksoy, 2008; Özkan ve ark., 2009; Tümsavaş ve Aksoy, 2009; Çakıcı ve ark., 2012; Özyazıcı ve ark., 2013a ve 2013b) toprakların, bitki besin maddesi seviyeleri ve verimlilik durumları incelenerek toprak özellikleri arasındaki ilişkiler ortaya konulmuş ve potansiyel bitki besleme sorunlarına çözüm önerileri geliştirilmiştir.

$\mathrm{Bu}$ çalışmanın amacı, Bingöl iline bağlı Merkez ilçe topraklarının temel verimlilik düzeylerini belirlemek ve sürdürülebilir toprak verimliliği ilkelerini ortaya koymaktır.

\section{Materyal ve Yöntem}

Araştırmanın materyalini, Bingöl ili Merkez ilçesi tarım topraklarından alınan toplam 29 adet toprak örneği oluşturmaktadır. Örnekleme noktalarına ait yer bildirim haritası Şekil 1'de verilmiştir. Toprak örnekleri genel kurallara uygun olarak (Jackson, 1958), 0-20 cm derinlikten paslanmaz çelik kürek ile alınmıştır. Alınan toprak örnekleri laboratuvar koşullarında temiz ambalaj kâğıtlarına serilerek, taş ve bitki parçacıkları ayıklanmış ve havada kurumaya bırakılmıştır. Kuruyan toprakların tamamı tahta tokmaklarla dövülerek $2 \mathrm{~mm}$ 'lik çelik elekten geçirilerek analizlere hazır hale getirilmiştir.

Toprak örneklerinin; kabaca bünye sınıfları, suyla doygunluk yöntemiyle (Richards, 1954); toprak reaksiyonu $(\mathrm{pH})$, hazırlanan saturasyon çamurunda cam elektrotlu $\mathrm{pH}$ metre ile ölçülerek (Richards, 1954); toprakların toplam tuz değerleri, saturasyon çamurundan çıkartılan ekstrakta kondaktivite cihazı ile ölçülmesiyle (Richards, 1954); kireç $\left(\mathrm{CaCO}_{3}\right)$ içerikleri, Scheibler kalsimetresi ile volümetrik metotla (Çağlar, 1949); organik madde, modifiye Walkley-Black yaş yakma yöntemiyle (Nelson ve Sommers, 1982); alınabilir P içerikleri, Olsen yöntemine göre (Olsen ve ark., 1954); alınabilir $\mathrm{K}$ içerikleri ise, toprak örneklerinin $1 \mathrm{~N}$ amonyum asetat $(\mathrm{pH}=7.0)$ çözeltisi ile ekstrakte edilmesiyle (Pratt, 1965) belirlenmiştir.

Araştırma alanından toplanan 29 toprak örneğine ait sonuçlarda temel tanımlayıcı istatistik analizleri uygulanmış, toprakların analiz sonuçları sınır değerlerine göre değerlendirilerek, toprak örneklerinin dağılımı ve oranları hesaplanmıştır. 


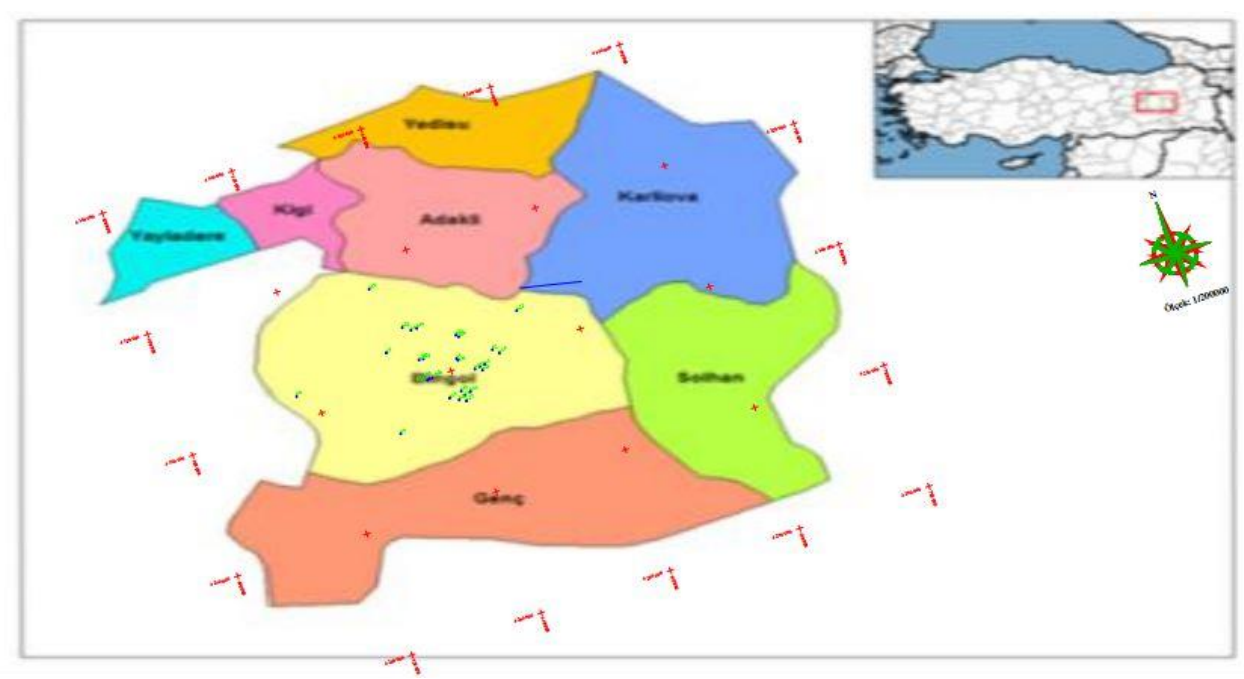

Şekil 1. Bingöl ili konumu ve toprak örnekleme noktaları

\section{Bulgular ve Tartışma}

Bingöl ili Merkez ilçe topraklarının bazı toprak özellikleri ve verimlilik düzeylerine ilişkin tanımlayıcı istatistikleri Tablo 1'de sunulmuştur. Tablo 1'de verilen çarpıklık katsayıları incelendiğinde; suyla doygunluk yüzdesi ve $\mathrm{pH}$ dışındaki kimyasal özelliklerin normal dağılımdan uzak pozitif dağılımlar gösterdiği görülmektedir. Bununla birlikte, incelenen toprak özelliklerinden toplam tuz, alınabilir $\mathrm{P}$ ve K'un kabul edilebilir ( \pm 2$)$ çarpıklık katsayısı gösterdiği belirlenmiştir. Tablo 1'de görüldüğü gibi varyasyon katsayıları (CV) çok farklılık göstermiştir. Wilding ve ark. (1994), toprak özelliklerindeki değişkenliğin göstergesi olan varyasyon katsayısını; $\mathrm{CV} \leq \% 15$ ise değişkenlik düşük, \% $16-30$ ise orta değişkenlik ve $\mathrm{CV} \geq \% 30$ ise değişkenlik yüksek olarak sınıflandırmaktadırlar. Buna göre araştırmada ele alınan toprak özellikleri değerlendirildiğinde; $\mathrm{pH}(\%$ 8.39) ve suyla doygunluk yüzdesi (\% 13.33) dışındaki incelenen diğer bütün toprak özelliklerinin yüksek değişkenliğe sahip olduğu, en fazla değişkenlik gösteren toprak özelliğinin kireç (\% 121.17) olduğu görülmektedir (Tablo 1). Toprak pH's1 yönünden saptanan bu bulgular; Özyazıcı ve ark. (2011), Sağlam ve ark. (2014) ve Dengiz ve ark. (2015)'nın bulgularıyla paralellik göstermektedir.

Araştırmada incelenen toprakların temel verimlilik özelliklerinin sınır değerlerine göre sınıflandırılması Tablo 2'de verilmiştir. Bingöl ili Merkez ilçe topraklarının suyla doygunluk değerleri \% 42 ile \% 68 arasında değişmekte olup, ortalama değeri \% 53 olarak bulunmuştur (Tablo 1). Suyla doygunluk yüzdelerine göre topraklar killi-tın ve tınlı topraklar sinıfina girmektedir (Tablo 2). İncelenen topraklar, tarım yönünden uygun fiziksel özelliklere sahip olup; toprakların su tutma kapasitesi, havalanması, gözenek yapısı ve su-hava dengesi, bitki gelişmesi açısından uygun durumda olduğu söylenebilir.

İncelenen tarım topraklarının $\mathrm{pH}$ değerleri 5.44-7.75 arasında değişkenlik göstermektedir (Tablo 1). Ülgen ve Yurtsever (1995)'e göre yapılan sınıflandırmaya göre; analiz edilen toprak örneklerinin \% 55.16'sının nötr, \% 34.48'inin hafif asit, \% 6.91'inin hafif alkalin ve \% $3.45^{\prime}$ 'inin ise orta asit karakterli olduğu (Tablo 2) belirlenmiştir.

Bingöl ili Merkez ilçe topraklarının toplam tuz değerleri $\% \quad 0.006$ ile $\% \quad 0.078$ arasında değişmektedir (Tablo 1). Richards (1954) tarafından yapılan sınıflandırmaya göre, araştırma topraklarının tamamının tuzsuz sınıfa girdiği görülmektedir (Tablo 2). Buna göre, araştırma topraklarının tuzluluk yönünden herhangi bir sorunu bulunmadığı, adı geçen tarım alanlarında birçok kültür bitkisinin rahatlıkla yetiştirebileceği anlaşılmaktadır.

Araştırma topraklarının kireç kapsamları \% 0.7-9.2 arasında değişmekte olup (Tablo 1), yapılan sınıflandırma (Ülgen ve Yurtsever, 1995) sonuçlarına göre; incelenen toprak örneklerinin \% 48.26'sının kireçli, \% 44.83'ünün az kireçli ve $\%$ 6.91'inin ise orta kireçli düzeyde olduğu belirlenmiştir (Tablo 2).

Yapılan analizler sonucunda Bingöl ili Merkez ilçesine ait tarım topraklarının organik madde kapsamlarının \% 0.03 ile \% 7.34 arasında değiștiğ saptanmıştır (Tablo 1). İncelenen toprakların büyük çoğunluğunun çok az, az ve orta düzeyde organik madde içerdiği belirlenmiştir (Tablo 2). Elde edilen bulgular Kızılgöz ve ark. (1999)'nın bulgularıyla paralellik göstermiştir. Yöre 
topraklarının organik madde seviyesinin iyileştirilmesi yönünde gerekli önlemlerin alınması, hem toprak verimliliği ve toprakların sürdürülebilirliği açısından ve hem de yetiştirilen ürünlerin verim ve kalitesi açısından büyük önem taşımaktadır.

Tablo 1. Bingöl ili merkez ilçesi tarım topraklarının verimlilik yönünden tamamlayıcı istatistikleri ( $\mathrm{n}=29)$

\begin{tabular}{|c|c|c|c|c|c|c|c|c|c|c|}
\hline $\begin{array}{l}\text { Toprak } \\
\text { özelliği }\end{array}$ & Birim & Ortalama & Varyans & SD & $\mathrm{CV}$ & $\begin{array}{c}\text { En } \\
\text { düşük }\end{array}$ & $\begin{array}{c}\text { En } \\
\text { yüksek }\end{array}$ & Çarpıklık & Basıklık & Ortanca \\
\hline $\begin{array}{l}\text { Suyla } \\
\text { doygunluk }\end{array}$ & $\%$ & 53 & 50.826 & 7.13 & 13.33 & 42 & 68 & 0.199 & -0.787 & 53.35 \\
\hline $\mathrm{pH}$ & & 6.68 & 0.324 & 0.57 & 8.39 & 5.44 & 7.75 & 0.016 & -0.383 & 6.64 \\
\hline $\begin{array}{l}\text { Toplam } \\
\text { tuz }\end{array}$ & $\%$ & 0.027 & 0.0001 & 0.013 & 65.00 & 0.006 & 0.078 & 1.995 & 6.531 & 0.026 \\
\hline $\begin{array}{l}\text { Kireç } \\
\left(\mathrm{CaCO}_{3}\right)\end{array}$ & $\%$ & 1.7 & 4.259 & 2.06 & 121.17 & 0.7 & 9.2 & 3.107 & 9.120 & 1.01 \\
\hline $\begin{array}{l}\text { Organik } \\
\text { madde }\end{array}$ & $\%$ & 1.80 & 2.201 & 1.48 & 82.68 & 0.03 & 7.34 & 2.387 & 7.307 & 1.68 \\
\hline $\begin{array}{l}\text { Alınabilir } \\
\text { P }\end{array}$ & $\mathrm{kg} \mathrm{P}_{2} \mathrm{O}_{5} \mathrm{da}^{-1}$ & 5.5 & 15.087 & 3.88 & 71.19 & 1.1 & 19.2 & 1.797 & 4.821 & 5.33 \\
\hline $\begin{array}{l}\text { Alınabilir } \\
\mathrm{K}\end{array}$ & $\mathrm{kg} \mathrm{K}_{2} \mathrm{O} \mathrm{da}{ }^{-1}$ & 120 & 3596.7 & 59.97 & 50.15 & 26 & 324 & 1.541 & 3.693 & 104 \\
\hline
\end{tabular}

Tablo 2. Toprak özelliklerinin sınır değerlerine göre sınıflandırılması

\begin{tabular}{|c|c|c|c|c|c|}
\hline Toprak özelliği & Birim & Sınır değeri & Değerlendirme & Örnek sayısı & $\%$ \\
\hline \multirow{5}{*}{$\begin{array}{l}\text { Suyla doygunluk } \\
\text { (Ülgen ve Yurtsever, 1995) }\end{array}$} & \multirow{5}{*}{$\%$} & $<30$ & Kum & - & 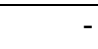 \\
\hline & & $31-50$ & Tin & 10 & 34.48 \\
\hline & & $51-70$ & Killi-tın & 19 & 65.52 \\
\hline & & $71-110$ & Kil & - & - \\
\hline & & $>110$ & Ağır kil & - & 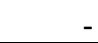 \\
\hline \multirow{6}{*}{$\begin{array}{l}\text { pH } \\
\text { (Ülgen ve Yurtsever, 1995) }\end{array}$} & & $<4.5$ & Kuvvetli asit & - & - \\
\hline & & $4.6-5.5$ & Orta asit & 1 & 3.45 \\
\hline & & $5.6-6.5$ & Hafif asit & 10 & 34.48 \\
\hline & & $6.6-7.5$ & Nötr & 16 & 55.16 \\
\hline & & 7.6-8.5 & Hafif alkali & 2 & 6.91 \\
\hline & & $>8.5$ & Kuvvetli alkali & - & - \\
\hline \multirow{4}{*}{$\begin{array}{l}\text { Toplam tuz } \\
\text { (Richards, 1954) }\end{array}$} & \multirow{4}{*}{$\%$} & $0.00-0.15$ & Tuzsuz & 29 & 100.00 \\
\hline & & $0.15-0.35$ & Hafif tuzlu & - & - \\
\hline & & $0.35-0.65$ & Orta tuzlu & - & - \\
\hline & & $0.65+$ & Çok tuzlu & - & _ \\
\hline \multirow{5}{*}{$\begin{array}{l}\text { Kireç }\left(\mathrm{CaCO}_{3}\right) \\
\text { (Ülgen ve Yurtsever, 1995) }\end{array}$} & \multirow{5}{*}{$\%$} & $0-1$ & Az kireçli & 13 & 44.83 \\
\hline & & $1-5$ & Kireçli & 14 & 48.26 \\
\hline & & $5-15$ & Orta kireçli & 2 & 6.91 \\
\hline & & $15-25$ & Fazla kireçli & - & - \\
\hline & & $>25$ & Çok fazla kireçli & - & - \\
\hline \multirow{5}{*}{$\begin{array}{l}\text { Organik madde } \\
\text { (Ülgen ve Yurtsever, 1995) }\end{array}$} & \multirow{5}{*}{$\%$} & $0-1$ & Çok az & 9 & 31.03 \\
\hline & & $1-2$ & $\mathrm{Az}$ & 9 & 31.03 \\
\hline & & $2-3$ & Orta & 9 & 31.03 \\
\hline & & $3-4$ & İyi & - & - \\
\hline & & $>4$ & Yüksek & 2 & 6.91 \\
\hline \multirow{5}{*}{$\begin{array}{l}\text { Alınabilir P } \\
\text { (Ülgen ve Yurtsever, 1995) }\end{array}$} & \multirow{5}{*}{$\mathrm{kg} \mathrm{P}_{2} \mathrm{O}_{5} \mathrm{da}^{-1}$} & $0-3$ & Çok az & 8 & 27.58 \\
\hline & & $3-6$ & $\mathrm{Az}$ & 11 & 37.92 \\
\hline & & $6-9$ & Orta & 7 & 24.14 \\
\hline & & $9-12$ & Yüksek & 1 & 3.45 \\
\hline & & $>12$ & Çok yüksek & 2 & 6.91 \\
\hline \multirow{4}{*}{$\begin{array}{l}\text { Alınabilir K } \\
\text { (Ülgen ve Yurtsever, 1995) }\end{array}$} & \multirow{4}{*}{$\mathrm{kg} \mathrm{K}_{2} \mathrm{O} \mathrm{\textrm {da } ^ { - 1 }}$} & $0-20$ & $\mathrm{Az}$ & - & - \\
\hline & & $20-30$ & Orta & 1 & 3.45 \\
\hline & & $30-40$ & Yeter & - & - \\
\hline & & $>40$ & Fazla & 28 & 96.55 \\
\hline
\end{tabular}


Araştırmada incelenen toprakların alınabilir $\mathrm{P}$ kapsamlarının 1.1-19.2 $\mathrm{kg} \quad \mathrm{P}_{2} \mathrm{O}_{5} \quad \mathrm{da}^{-1}$ arasında değişkenlik gösterdiği saptanmıştır (Tablo 1). Tablo 2'nin incelenmesinden de anlaşılacağı üzere; alının toprak örneklerinin \% 65.50'sinin çok az ve az, \% 24.14'ünün orta ve \% 10.36'sının ise yüksek ve çok yüksek düzeyde alınabilir $\mathrm{P}$ içerdiği tespit edilmiştir. Elde edilen sonuçlar Saraçoğlu ve ark. (2014)'nın bulgularıyla benzerlik göstermektedir.

Bingöl ili Merkez ilçe topraklarının alınabilir K kapsamları 26-324 $\mathrm{kg} \mathrm{K}_{2} \mathrm{O} \mathrm{da}^{-1}$ arasında değiştiği belirlenmiştir (Tablo 1). Analiz edilen toprakların büyük çoğunluğunda alınabilir potasyum miktarları yüksek bulunmuştur. Benzer sonuçlar Çimrin ve Boysan (2006) ve Parlak ve ark. (2008) tarafından da elde edilmiştir.

\section{Sonuçlar}

Bingöl ili Merkez ilçesi tarım topraklarının verimlilik düzeylerini belirlemek amacıyla yapılan bu çalışmanın sonuçlarına göre; toprakların bünye sınıfının killi-tın ve tınlı yapıda olduğu, toprak pH'sının büyük çoğunluğunun hafif asit ve nötr karakterli olduğu görülmüştür. Tuzluluk problemi bulunmayan yöre topraklarının organik madde bakımından yetersiz, kireç ve alınabilir $\mathrm{P}$ yönünden düşük, alınabilir $\mathrm{K}$ bakımından ise yeterli düzeyde olduğu anlaşılmaktadır. Toprakların organik maddece zenginleşmesi için çiftlik gübresi, organik gübreler ve toprak düzenleyici bazı organo mineral gübrelerin kullanılması toprak verimliliği ve bitki besleme açısından önem taşımaktadır. Yörede toprak analizlerine gereken önem verilmeli ve analiz sonuçlarına göre özellikle azotlu ve fosforlu gübrelerin uygun cins ve miktarları gübreleme programlarına alınmalıdır.

\section{Kaynaklar}

Adiloğlu, A., Adiloğlu, S., 2004. An investigation on nutritional problems of hazelnut (Corylus avellana) grown in acid soils of Turkey. Pakistan Journal of Biological Sciences, 7(8): 1433-1437.

Başar, H., 2001. Bursa ili topraklarının verimlilik durumlarının toprak analizleri ile incelenmesi. Uludă̆ Üniversitesi Ziraat Fakültesi Dergisi,15(2): 69-83.

Çağlar, K.Ö., 1949. Toprak Bilgisi. Ankara Üniversitesi, Ziraat Fakültesi Yayınları No: 10.

Çakıcı, H., Çiçekli, M., Arslan, H., 2012. Bağyurduİzmir yöresi kiraz plantasyonlarının beslenme durumu. Ege Üniversitesi Ziraat Fakültesi Dergisi, 49(1): 7-15.

Çimrin, K.M., Boysan, S., 2006. Van yöresi tarım topraklarının besin elementi durumları ve bunların bazı toprak özellikleriyle ilişkileri. Yüzüncü Yll
Üniversitesi Ziraat Fakültesi Tartm Bilimleri Dergisi, 16(2): 105-111.

Demirer, T., Kaleli, Ş., Öztokat Kuzucu, D.C., 2003. A study to determine fertility status in the ÇanakkaleLapseki agricultural areas, Turkey. Journal of Arid Environments, 54: 485-493.

Dengiz, O., Özyazıc1, M.A., Sağlam, M., 2015. Multicriteria assessment and geostatistical approach for determination of rice growing suitability sites in Gokirmak catchment. Paddy and Water Environment, 13(1): 1-10.

Eyüpoğlu, F., Kurucu, N., Talaz, S., 1996. Türkiye topraklarının bitkiye yarayışlı bazı mikro elementler (Fe, $\mathrm{Cu}, \mathrm{Mn}, \mathrm{Zn}$ ) bakımından genel durumu. Toprak ve $\mathrm{Su}$ Kaynakları Araştırma Yıllı̆̆ı-1995. T.C. Başbakanlık Köy Hizmetleri Genel Müdürlüğü APK Dairesi Başkanlığı, Toprak ve Su Kaynakları Araştırma Şube Müdürlüğü, Yayın No: 98, Ankara, s. 338-350.

Jackson, M.L., 1958. Soil Chemical Analysis. Englewood Cliffs, NJ: Prentice- Hall. Inc.

Kızılgöz, İ., Kızılkaya, R., Açar, İ., Seyrek, A., Kaptan, H., 1999. Şanlıurfa yöresinde antepfistı̆̆ 1 (Pistacia vera) yetiștirilen toprakların verimlilik düzeylerinin saptanması üzerine bir araştırma. GAP 1. Tarım Kongresi, II. Cilt, 26-28 Mayıs, Şanlıurfa, s. 987994.

Nelson, D.W.,Sommers, L.E., 1982. Total Carbon, Organic Carbon, Organic Matter. In: AL Madison, Editor. Methods of Soil Analysis Part 2. Chemical and Microbiological Properties Second Edition. Wisconsin, USA: American Society of Agronomy Inc. pp. 539-579.

Olsen, S.R., Cole, C.V., Watanabe, F.S., Dean, L.A.,1954. Estimation of available phosphorus in soils by extraction with sodiumbicarbonate. USDA CircularNr 939, US Gov. Print. Office, Washington, D.C.

Özkan, C.F., Arpacıŏglu, A.E., Arı, N., Demirtaş, E.I., Asri, F.Ö., 2009. Antalya bölgesinde elma yetiştirilen toprakların verimlilik durumlarının incelenmesi. Tarım Bilimleri Araştırma Dergisi, 2(2): 95-99.

Özyazıc1, M.A., Özyazıc1, G., Dengiz, O., 2011. Determination of micronutrients in tea plantations in the Eastern Black Sea region, Turkey. African Journal of Agricultural Research, 6(22): 5174-5180.

Özyazıcı, M.A., Dengiz, O., Sağlam, M., 2013a. Artvin ilinde yonca (Medicago sativa L.) tarımı yapılan toprakların verimlilik durumu ve potansiyel beslenme problemlerinin ortaya konulmasi. Artvin Çoruh Üniversitesi Orman Fakültesi Dergisi, 14(2): 225-238.

Özyazıcı, M.A., Aydoğan, M., Bayraklı, B., Dengiz, O., 2013b. Doğu Karadeniz bölgesi kırmızi-sar1 podzolik toprakların temel karakteristik özellikleri ve verimlilik durumu. Anadolu Tarm Bilimleri Dergisi, 28(1): 24-32.

Parlak, M., Fidan, A., Kızılcık, İ., Koparan, H., 2008. Eceabat ilçesi (Çanakkale) tarım topraklarının verimlilik durumlarının belirlenmesi. Ankara 
Üniversitesi Ziraat Fakültesi Tarım Bilimleri Dergisi, 14(4): 394-400.

Pratt, P.F., 1965. Potassium. In: C.A. Black (Ed). Methods of Soil Analysis Part 2. Chemical and Microbiological Properties. American. Society. Agronomy., Inc., Madison, pp. 1022-1030.

Richards, L.A., 1954. Diagnosis and Improvoment of Saline and Alkaline Soils. U.S.A: U.S. Department of Agriculture, Handbook 60.

Sağlam, M., Dengiz, O., Özyazıcı, M.A., Erkoçak, A., Türkmen, F., 2014. Faktör analizi ile minimum veri setinin oluşturulması ve haritalanması: Samsun ili örneği. Ege Üniversitesi Ziraat Fakültesi Dergisi, 51(2): 133-144.

Saraçoğlu, M., Sürücü, A., Koşar, A., Tas, M.A., Aydoğdu, M., Kara, H., 2014. Şanlıurfa ili Halfeti ilçesi topraklarının bazı özellikleri ve bitki besin elementi kapsamlarının belirlenmesi. Toprak Bilimi ve Bitki Besleme Dergisi, 2(1): 38-45

Sungur, M., Özuygur, M., 1986. Türkiye topraklarının mikro element durumu hakkında bir araştırma. Toprak İlmi Derneği 9. Bilimsel Toplantı Tebliğleri, Yayın No: 4, 29-1.

Taban, S., Çıkılı, Y., Cebeci, F., Taban, N., Sezer, S.M., 2004. Taşköprü yöresinde sarımsak tarımı yapılan toprakların verimlilik durumu ve potansiyel beslenme problemlerinin ortaya konulmasi. Tarım Bilimleri Dergisi, 10(3): 297-304.
Tarakçıoğlu, C., Yalçın, S.R., Bayrak, A., Küçük, M., Karabacak, H., 2003. Ordu yöresinde yetiştirilen findık bitkisinin (Corylus avellana L.) beslenme durumunun toprak ve yaprak analizleriyle belirlenmesi. Tarım Bilimleri Dergisi, 9(1): 13-22.

Tümsavaş, Z., Aksoy, E., 2008. Bursa yöresi rendzina büyük toprak grubu topraklarının bazı özellikleri ve besin maddesi içerikleri. Uludağ Üniversitesi Ziraat Fakültesi Dergisi, 22(1): 95-106.

Tümsavaş, Z., Aksoy, E., 2009. Kahverengi orman büyük toprak grubu topraklarının verimlilik durumlarının belirlenmesi. Uluda $\breve{g}$ Üniversitesi Ziraat Fakültesi Dergisi, 23(1): 93-104.

Ülgen, N., Yurtsever, N., 1995. Türkiye Gübre ve Gübreleme Rehberi (4. Baskı). T.C. Başbakanlık Köy Hizmetleri Genel Müdürlüğü Toprak ve Gübre Araştırma Enstitüsü Müdürlüğü Yayınları, Genel Yayın No: 209, Teknik Yayınlar No: T.66, Ankara.

Wilding, L.P., Bouma, J., Gross, D.W., 1994. Impact of spatial variability on interpretative modelling. In: Quantitative Modelling of Soil Forming Processes R.B. Bryantand Arnold R.W. (ed), SSSA Special Publication Number 39, SSSA, Inc. Madison Wisconsin, USA.

Zengin, M., Çetin, Ü., Ersoy, İ., Özaytekin, H.H., 2003. Beyşehir yöresi tarım topraklarının verimlilik durumlarının belirlenmesi. Selçuk Üniversitesi Ziraat Fakültesi Dergisi, 17(31): 24-30. 